\title{
ESTIMATION OF SNOW DEPLETION CURVE FOR GANGOTRI BASIN USING MULTI-SOURCE REMOTE SENSING DATA
}

\author{
Prateek Verma ${ }^{1,2, *}$, Sanjay Kumar Ghosh², RAAJ Ramsankaran ${ }^{1}$ \\ ${ }^{1}$ Indian Institute of Technology Bombay, Mumbai, India - 400076 (*vermprateek@gmail.com) \\ ${ }^{2}$ Indian Institute of Technology Roorkee, Uttarakhand, India - 247667
}

Commission III, WG III/9

KEY WORDS: Snow Depletion Curve, NDSI, Sentinel-3A, Sentinel-2A, Landsat 8, MODIS MOD10A1 product

\begin{abstract}
:
Snow Depletion Curve derived from satellite images is a key parameter in Snowmelt Runoff Model. The fixed temporal resolution of a satellite and presence of cloud cover in Himalayas restricts accuracy of generated SDC. This study presents an effective approach of reducing temporal interval between two consecutive dates by integrating normalized Snow Cover Area estimated from multiple sources of satellite data. SCA is extracted by using Normalized Difference Snow Index for six snowmelt seasons from 2013 to 2018 for Gangotri basin situated in Indian Himalayas. This work also explores potential of recently launched Sentinel-3A for estimating SCA. Normalized SCA is utilized to eliminate the effect of difference in spatial resolution of various satellites. The result develops an important linear relation between SDC and time with a decrease in snow cover of $0.005 /$ day that may be further refined by increasing the number of snowmelt seasons. This relationship may help scientific community in understanding hydrological response of glaciers to climate change.
\end{abstract}

\section{INTRODUCTION}

The distribution in spatio-temporal variation of Snow Cover Area (SCA) is an extremely important information for modelling daily snowmelt from a glacier (Salomonson and Appel, 2004). The information of SCA is used to develop Snow Depletion Curve (SDC) for a glacier, which is an important input to hydrological modelling. Generally, generation of daily streamflow from glacierized region is focused only on the snowmelt period (Dressler et al., 2006). It is observed that SCA decreases gradually with time during the snowmelt season and accurate representation of this gradual decrease in SCA may result in good predictions for various purposes such as flood forecasting and hydropower generation (Kolberg and Gottschalk, 2006).

SCA of a glacier plays a key role in estimating and forecasting daily stream flow for a mountainous basin where snow melt is an important runoff factor. Several studies have utilized satellite data for runoff analysis by estimating SCA for different glaciers worldwide (Immerzeel et al., 2009; Aggarwal et al., 2014; Tiwari et al., 2015; Firouzi and Sadeghian, 2016; Steele et al., 2017; Kulshrestha et al., 2018). Immerzeel et al., (2009) used snow cover products available from Moderate Resolution Imaging Spectroradiometer (MODIS) for large scale monitoring of snow cover and simulation of runoff for Himalayan river basins comprising of Indus, Irrawaddy, Ganges, Salween, Brahmaputra, Yangtze, Yellow and Mekong from 2000 to 2008. Aggarwal et al., (2014) integrated temporal SCA derived from MODIS, Landsat and Advanced Wide Field Sensor (AWiFS) dataset with Digital Elevation Model (DEM) and estimated snowmelt runoff for Alaknanda and Bhagirathi river basins in Uttarakhand state of India.

Tiwari et al., (2015) carried out a study on examining interannual variability of snowmelt for the runoff estimation in Satluj

*Corresponding author basin using Snow Water Equivalent (SWE) derived from satellite images of Scanning Multichannel Microwave Radiometer (SMMR) and Special Sensor Microwave/Imagers (SSM/I) sensors by National Snow and Ice Data Centre (NSIDC) from 1979-2007. Firouzi and Sadeghian, (2016) examined the capability of Snowmelt Runoff Model (SRM) by using remote sensing data derived from MODIS SDC for simulating and modelling the streamflow for Samalghan basin of Atrak river located in Iran. Steele et al., (2017) used MODIS snow products for simulating snowmelt runoff for Upper Rio Grande headwater basin in Colorado from 2001 to 2011. Kulshrestha et al., (2018) studied the effect of temporal variation in near surface lapse rate on degree-day SRM for cold desert region of Spiti river basin in Himalayas by utilizing MODIS Terra 8-day MOD10A2 dataset for 2001, 2002, 2004 and 2005.

Hence, monitoring of SCA on a regular interval can be carried out by using satellite data for generation of SDC for the glacier. Due to fixed temporal resolution of a satellite, SCA is estimated only on a periodical time interval. This time interval gets further increased if there is presence of clouds in satellite data over the study area. Further, the periodical values of SCA are interpolated for generation of SDC on a daily scale to provide input to SRM model. The presence of highly variable weather system at high mountainous region of Himalayas results in different rate of snowmelt at different period of time in a day or consecutive days. Therefore, use of interpolation approach to estimate SCA at daily scale introduces a significant amount of error in SDC. The fresh occurrence of snowfall also gets unaccounted in interpolation technique if it occurs between two consecutive acquisitions of satellite data.

The existence of above two discussed problems can be minimized if satellite data from multiple sources is considered instead of single source. Due to different temporal resolution of each satellite, it is observed that different satellites visit a particular area generally on different dates and time. Thus, use of satellite data from multiple sources may help in reducing 
temporal interval between satellite data of consecutive dates for estimation of SCA.

This work presents the study of normalized SDC by reducing significantly the temporal interval between two consecutive days by integrating satellite data from multiple sources. The study also discusses about the relationship that has been established between SCA and time period during a snowmelt season. The normalized values of SCA has been utilized in this study in order to eliminate the effect of difference in spatial resolution of these satellites. The present investigation also explores the potential of recently launched Sentinel-3A satellite for estimation of SCA. With a temporal resolution of less than two days, snow cover products generated from Sentinel-3A may prove to be very helpful in development of SDC. The aim of this proposed research is to increase the understanding about nature of variation in average SDC of Gangotri basin.

\section{STUDY AREA}

Gangotri basin is the source of River Bhagirathi and is located between $30^{\circ} 43^{\prime} \mathrm{N}$ to $31^{\circ} 01^{\prime} \mathrm{N}$ latitude and $78^{\circ} 59^{\prime} \mathrm{E}$ to $79^{\circ} 17^{\prime} \mathrm{E}$ longitude (Verma and Ghosh, 2019a). The total area and perimeter occupied by Gangotri basin has been estimated to be around $549.25 \mathrm{~km}^{2}$ and $222.53 \mathrm{~km}$, respectively (Tangri et al., 2004). Gangotri glacier, situated in Uttarkashi district of Uttarakhand, is one of the largest glacier in Central Himalaya which flows in North-West direction (Verma and Ghosh, 2019b). The estimated total area of the glacier is $143.58 \mathrm{~km}^{2}$, having a mean elevation of 6200 and $4800 \mathrm{~m}$ above msl for accumulation and ablation zone respectively (Srivastava, 2012).

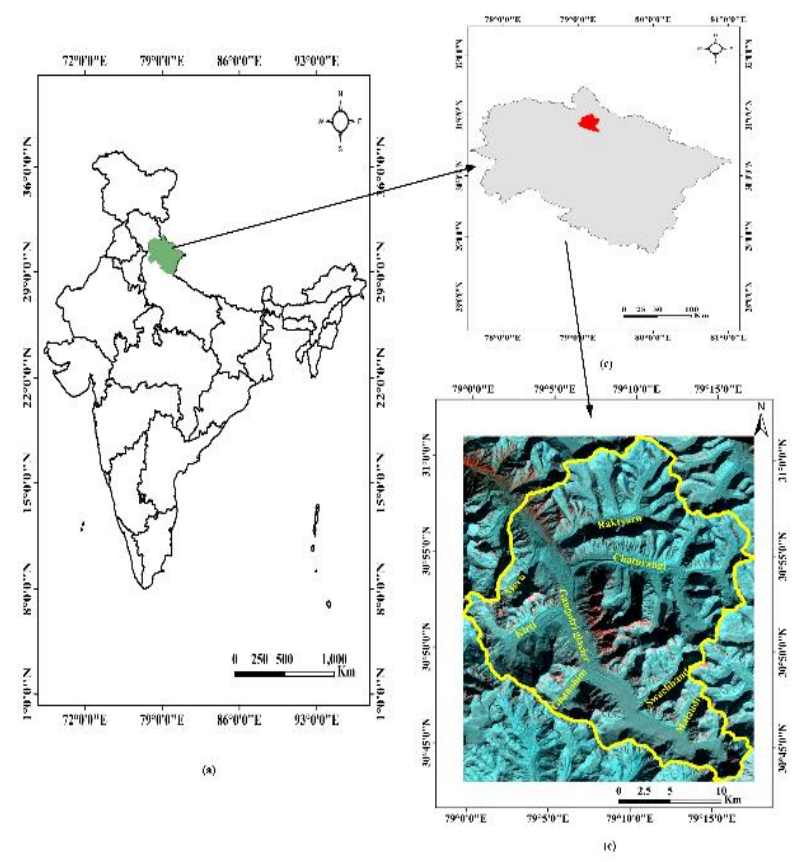

Figure 1. Study area (a) Map of India (b) Map of Uttarakhand with Gangotri basin boundary (red color) (c) Standard FCC of Gangotri glacier with tributary glaciers

\section{DATA USED}

In this study, optical satellite data from four different sources i.e. Landsat 8, Sentinel-2A, Sentinel-3A and MODIS MOD10A1 snow cover product have been used. SDC has been generated from $1^{\text {st }}$ of May to $30^{\text {th }}$ September for a period of 6 years from
2013 to 2018. The selection of satellite data is based on two criterias: firstly, study area should be cloud free in the satellite image and secondly if cloud free image from multiple sources is available for the same dates then data from fine resolution source is considered. If there is no data available for first and last day of snow melt season, then cloud free dataset from April (i.e. satellite data closest to $1^{\text {st }}$ May) and October (i.e. satellite data closest to $30^{\text {th }}$ September) have been used for estimation of SCA using interpolation techniques. Hence, this study has been carried out for six snow melt seasons from 2013 to 2018 for estimation of normalized values of SCA (Table 1).

\begin{tabular}{|c|c|c|c|c|}
\hline Year & $\begin{array}{c}\text { Landsat } \\
\mathbf{8}\end{array}$ & MODIS & $\begin{array}{c}\text { Sentinel- } \\
\text { 2A }\end{array}$ & $\begin{array}{c}\text { Sentinel- } \\
\text { 3A }\end{array}$ \\
\hline 2013 & 4 & 18 & - & - \\
\hline 2014 & 5 & 23 & - & - \\
\hline 2015 & 6 & 28 & - & - \\
\hline 2016 & 5 & 15 & 2 & - \\
\hline 2017 & 7 & 22 & - & 5 \\
\hline 2018 & 5 & 8 & 7 & 4 \\
\hline
\end{tabular}

Table 1. Number of satellite data used to estimate SCA during six snowmelt seasons from 2013 to 2018

Since Sentinel-3A mission is recently launched program, hence this study contains detailed discussion on data and methodology adopted for estimation of SCA from Sentinel-3A. Sentinel-3A, developed by European Space Agency (ESA) under Copernicus Programme, was launched on $16^{\text {th }}$ February 2016. Sentinel-3A is an ocean and land mission, which makes use of multiple sensing instruments i.e. Ocean and Land Color Instrument (OLCI), Sea and Land Surface Temperature Radiometer (SLSTR), SAR Altimeter (SRAL), Doppler Orbitography and Radiopositioning Integrated by Satellite (DORIS) and Microwave Radiometer (MWR). The OLCI instrument measures solar radiation reflected by Earth at a ground resolution of $300 \mathrm{~m}$ in 21 spectral bands while SLSTR instrument acquire images at $500 \mathrm{~m}$ resolution for solar reflectance bands and $1 \mathrm{~km}$ resolution for thermal infrared bands. The OLCI sensor provides satellite data in visible and near-infrared region, while SLSTR sensor provide data in SWIR and thermal regions.

\section{METHODOLOGY}

The methodology for generation of SDC from multi-resolution satellite data has been discussed in Fig. 2. The methodology regarding use of satellite data acquired by Landsat 8 , Sentinel-2 and MODIS MOD10A1 snow cover product for extraction of snow cover information using NDSI has been discussed and well established already in several articles (Immerzeel et al., 2009; Aggarwal et al., 2014; Zhu et al., 2015). Therefore, this study only includes detailed discussion on use of recently launched Sentinel-3A satellite data for estimation of SCA (Fig. 3).

However, estimation of SCA obtained from each source has been validated by comparing it with SCA estimated from other sources for the same dates. The snow cover information extracted from satellite data of multiple sources have been compiled together for detection of a specific trend in temporal variation of SCA for snowmelt season extending from May to September. 


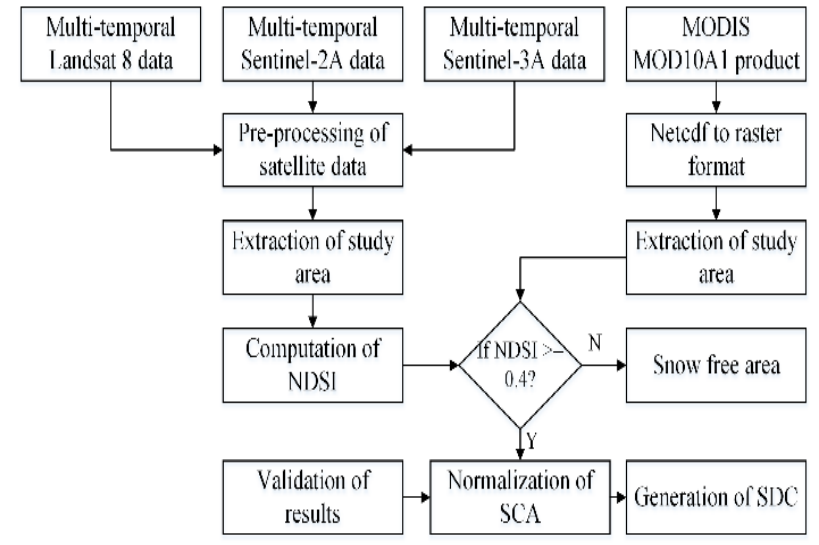

Figure 2. Flowchart of methodology followed for generation of SDC using satellite data from multiple sources

\subsection{Pre-processing of Sentinel-3A data}

The pre-processing of satellite data is necessary to convert radiance into reflectance by using radiance to reflectance tool for Sentinel-3A available in SNAP platform. Earth Observation (EO) processing output of Level 1 Sentinel-3A image is radiometrically calibrated, geo-referenced and annotated radiances. The pre-processing module derives reflectance corrected for gaseous absorption and atmospheric correction. As per information provided in technical guide of Sentinel-3 mission ${ }^{1}$, the process of conversion of radiance to reflectance includes three main steps:

i. The first step consists of pre-processing of Sentinel-3A imagery for geometry and meteorological parameters. Different meteorological parameters are derived at each pixel (including invalid ones) with the help of annotation product.

ii. The second step consists of conversion of Level-1B pixel classification to Level-2 pixel identification product using INVALID flag of Level-1B product. If this flag is set to TRUE, no further processing of that pixel is performed and next pixel is examined, otherwise processing of current pixel is continued.

iii. The third step includes pixel extraction and reflectance conversion using sun zenith angle cosine interpolated at the pixel and sun spectral flux read from annotations file.

The first step after pre-processing is selection of Green and SWIR bands to estimate NDSI. Green band is selected and extracted from available 21 spectral bands of OLCI while SWIR band is selected and extracted from available 11 bands of SLSTR sensor by using Band Select tool available in SNAP platform. Further, the two selected bands are re-projected to UTM/WGS84 projection system and later SWIR band is resampled to $300 \mathrm{~m}$ to bring both bands to same spatial resolution.

The layer stacked image is converted into tiff format for computation of SCA by using NDSI. A threshold value of 0.4 is considered for separating snow and non-snow areas of Gangotri basin (Negi et al., 2010). The methodology adopted for preparation of Sentinel-3A data to compute NDSI values is shown in the flowchart (Fig. 3). The layer stacked multispectral image of Sentinel-3A obtained from Fig. 3 is further used to estimate NDSI values (Fig. 2).

${ }^{1}$ https://sentinel.esa.int/web/sentinel/technicalguides/sentinel-3olci/level-/radiance-to-reflectance-conversion

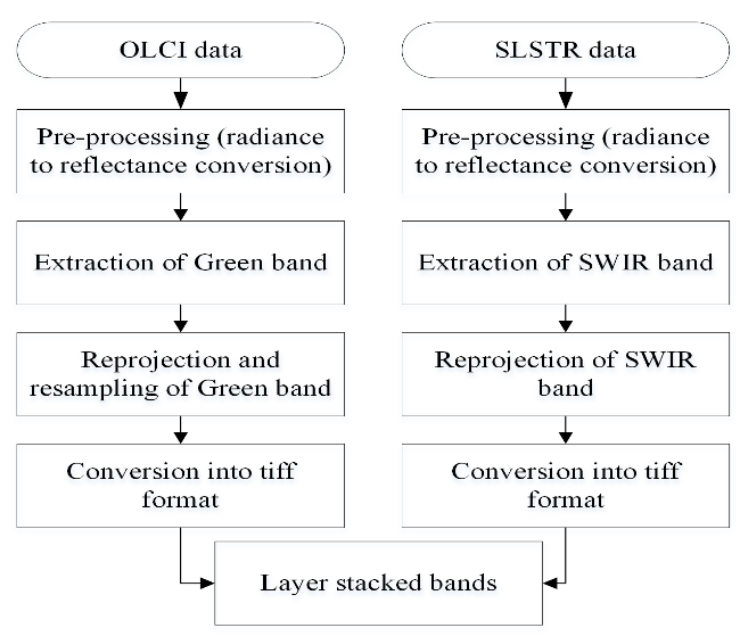

Figure 3. Flowchart for pre-processing of Sentinel-3A dataset

\subsection{Computation of NDSI}

The layer stacked pre-processed satellite data of Sentinel-3A, Sentinel-2A and Landsat 8 is used to compute NDSI values for estimation of SCA. NDSI value ranges from -1 to +1 and is computed by using the relationship:

$$
N D S I=\frac{\text { Green band }-S W I R \text { band }}{\text { Green band }+S W I R \text { band }}
$$

Here, band 6 (Green) of OLCI data and band 5 (SWIR) of SLSTR data were used to generate NDSI image of Sentinel-3A. For Landsat 8, surface reflectance band 3 (Green) and band 6 (SWIR) were used to estimate SCA by using NDSI. To calculate NDSI for Sentinel-2A imagery, band 3 (Green) and band 11 (SWIR) were used. The already prepared snow cover product MOD10A1 from MODIS were downloaded from Earthdata. The surface reflectance product of Landsat 8 was obtained from EarthExplorer at United States Geological Survey (USGS) by following standard procedure. The detailed description about pre-processing of Sentinel-2A imagery is discussed in Verma and Ghosh, (2019a). Similar steps were followed for preprocessing of Sentinel-2A dataset for converting radiance to reflectance.

\subsection{MODIS MOD10A1 snow cover product}

MOD10A1 product from MODIS onboard Terra satellite provides gridded snow cover dataset at daily scale with a spatial resolution of $500 \mathrm{~m}$. Generally, MOD10A1 version 6 snow cover product is provided in netcdf format with different values ranging from 0 to 255 representing different information. Firstly, product file is converted into raster format in ArcGIS environment. Further, area of interest is masked out from the tile to extract information about the study area. The masked snow cover product is further analyzed to know the presence of cloud cover/snow cover over the study area. The presence of clouds over the study area leads to rejection of that particular tile. The pixels of MOD10A1 snow cover product represents NDSI values in the form of percentage ranging from 0 to 100 . Snow cover in MOD10A1 product is detected by using NDSI algorithm where pixel with NDSI $>0.0$ is considered to contain some snow and pixel with NDSI $\leq 0.0$ is considered to be snow free surface. However, a pixel with NDSI $>0.0$ undergoes further checks before getting declared as snow cover pixel. Since, NDSI threshold value of 0.4 has been considered for segregation between snow and snow free area, therefore a percentage value 
of greater than or equal to $40 \%$ is considered as snow cover region in the area of interest. The methodology adopted for extraction of snow cover information from MOD10A1 product has been shown in Fig. 2.

\subsection{Normalization of SCA}

The normalization of snow cover values is an extremely important step to bring SCA results obtained from different satellites to a common scale. The normalization process is carried out using the following relation:

$$
y=\frac{x-x_{\min }}{x_{\max }-x_{\min }}
$$

where y is normalized SCA value, $x$ is actual SCA value, $x_{\text {min }}$ and $x_{\max }$ are minimum and maximum value of SCA for a particular year.

\section{RESULTS AND DISCUSSIONS}

The snow cover values obtained from different sources were first normalized to eliminate the effect of difference in spatial resolution. Further, these normalized values were arranged in a tabular form and data gaps were filled using interpolation method to prepare SDC on a daily scale. The normalized SCA curve obtained from MODIS product and final SCA curve from all sources is compared for 2018 (Fig. 4).

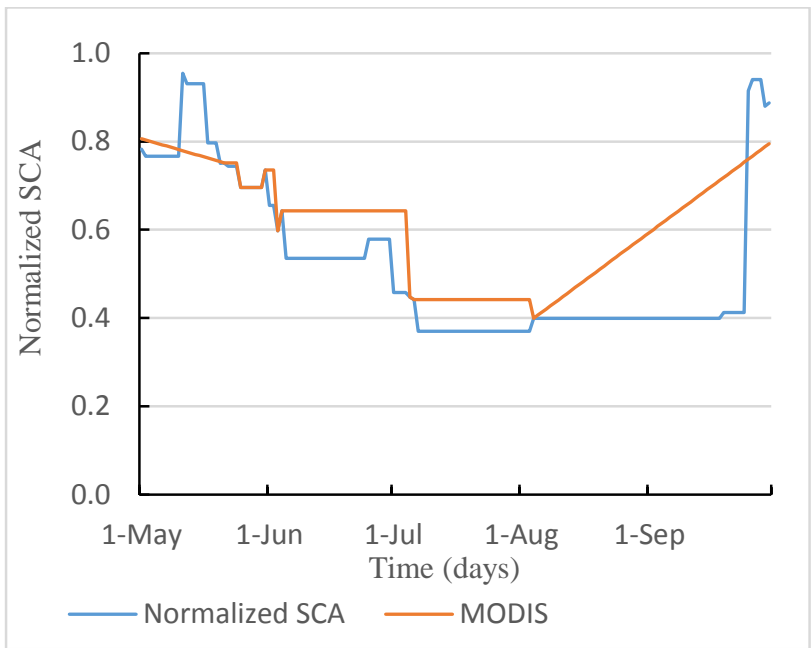

Figure 4. Comparison of normalized SCA obtained from MODIS MOD10A1 and SCA curve from all sources for 2018

Fig. 5 represents individual SDC for six snowmelt seasons and average SDC obtained by estimating average values of normalized SCA for each year over the basin. From SDC, it is envisaged to develop a relationship to express the variation of SDC with time. The average SDC gives a better understanding of the nature of variation in snow cover in comparison to SDC for each individual season.

Average SDC provides the advantage of minimizing the effect of outliers in the analysis of normalized snow cover values at daily scale. The technique of regression analysis is performed to represent average SDC in mathematical form by generating trend line for the curve. The trend for average SDC indicates a decrease of 0.003 day in normalized value of snow cover from entire six snowmelt seasons with $\mathrm{R}^{2}$ value of 0.73 . Here, it is observed that application of regression analysis on SDC for entire snowmelt season results in medium $\mathrm{R}^{2}$ value. Thus, visual inspection of average SDC shows that the curve follows different nature of variation during different period of time as evident from Fig. 5. Therefore, the curve has been divided into three parts for better understanding and representation of result (Fig. 6). Further, it is observed that division of curve into three parts results in better $\mathrm{R}^{2}$ value from May to July where snowmelt is the major factor for the runoff.

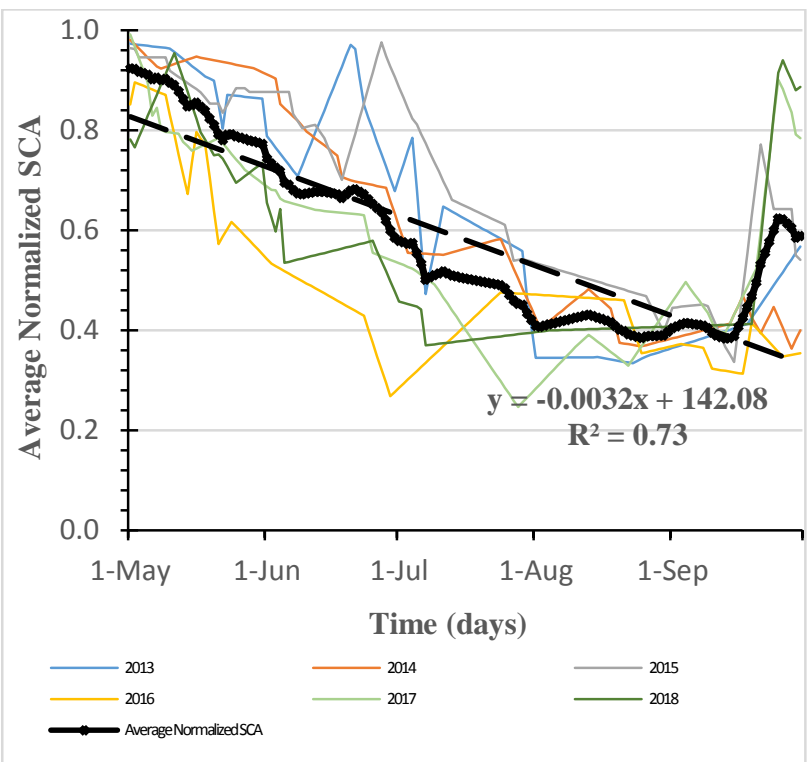

Figure 5. SDC for melt season of 2013 to 2018 and average normalized SCA for a period of 6 years

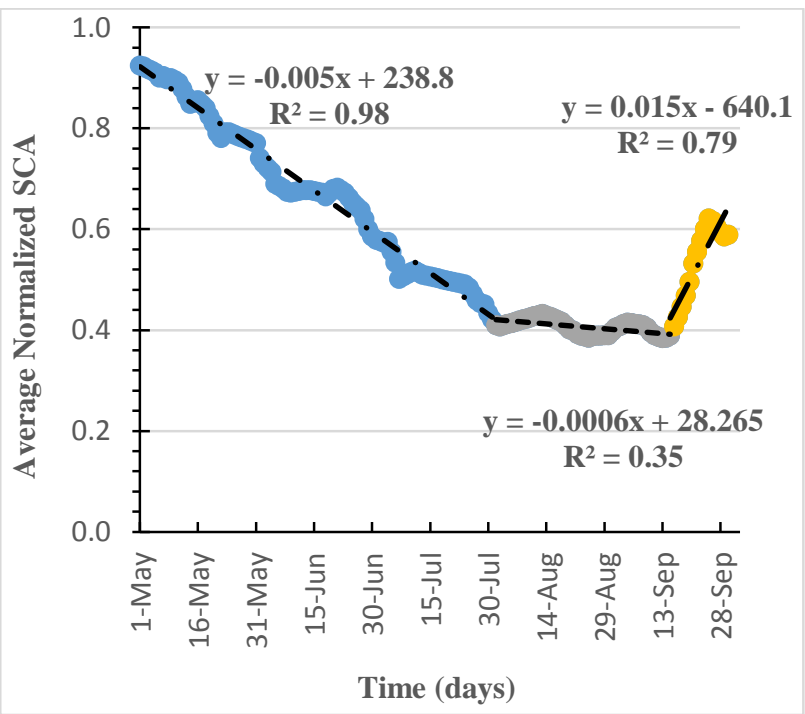

Figure 6. Division of average SDC in three parts for entire snowmelt season

Firstly, the curve shows a steep decrease in normalized snow cover values from May to July due to presence of summer season in the region where temperature show a significant increase from May to July. The second part starts from August and ends in mid of September where the curve remains almost flat due to start of monsoon season in the region. The presence of clouds for major part of the duration blocks the sunlight and hence result in significant decrease in rate of snow melt during monsoon season. The third part of SDC starts from mid of September till end of 
snowmelt season where temperature show a significant decrease and some events of snowfall occurs. This results in sharp increase in SDC during this period of time. Overall, average SDC clearly indicates that normalized snow cover is at its peak with the start of the snow melt season and gradually goes on decreasing till end of July (Fig. 4). Fig. 5 represents three parts of average SDC with three different colors. Each part of the plot has been accompanied by a mathematical equation giving the slope of trend line and $\mathrm{R}^{2}$ value (Table 2 ).

\begin{tabular}{|c|c|c|}
\hline Time Period & Mathematical Expression & $\mathbf{R}^{2}$ \\
\hline $1^{\text {st }}$ May to $30^{\text {th }}$ Sept & $\mathrm{Y}=-0.0032 \mathrm{x}+142.08$ & 0.73 \\
\hline $1^{\text {st }}$ May to $31^{\text {st }}$ July & $\mathrm{Y}=-0.005 \mathrm{x}+238.8$ & 0.98 \\
\hline
\end{tabular}

Table 2. Variation of SDC for different time periods in a snow melt season

A high value of $\mathrm{R}^{2}$ is desired for better fitting of regression line to normalized snow cover values. The $x$ and $y$ axis represents time and normalized snow cover value of average SDC respectively. The equation for first part (i.e. $\mathrm{y}=-0.005 \mathrm{x}+238.8$ ) of SDC shows a decrease in slope of trend line by $0.005 /$ day from May to July with a very high $\mathrm{R}^{2}$ value of 0.98 . The slope of second part (i.e. $y=-0.0006 x+28.26$ ) indicates almost a flat line with a very small negative value of $0.0006 /$ day from August to mid of September with a low $\mathrm{R}^{2}$ value of 0.35 . The third part of average SDC (i.e. $y=+0.015 x+640.1$ ) shows a sharp increase from mid to end of September with a positive slope of $0.015 /$ day and $R^{2}$ value of 0.79 . The main focus of improvement in $R^{2}$ value was only first snow melt period extending from $1^{\text {st }}$ May to $31^{\text {st }}$ July where snowmelt occurs mostly because of temperature increase during summer season.

The estimation of SCA using newly launched Sentinel-3A satellite data is validated by comparing with MODIS snow cover product MOD10A1 for same dates (Table 3 ). The results are compared based on spatial extent of snow cover (Fig. 6) and normalized SCA values obtained from both datasets (Table 3 ). The validation of results is done for two time instance i.e. one for 4 June 2017 and second for 29 September 2018 considering the snowmelt and snowfall period in the season.

The result from Sentinel-3A data shows close agreement with MODIS snow cover product in terms of both spatial extent of snow cover (Fig. 6) and normalized values of SCA (Table 3). The normalized values for 29 September 2018 and 4 June 2017 shows a difference of only 0.01 and 0.02 respectively (Table 3 ). However, by comparing the spatial extent of SCA in Fig. 6, it is observed that few snow free pixels are present at wrong locations in all the images. Here, manual inspection verifies the presence of clouds on these snow free pixels. Hence, close agreement between MODIS MOD10A1 and Sentinel-3A results validate the algorithm used for estimation of SCA from Sentinel-3A dataset.

\begin{tabular}{|c|c|c|}
\hline $\begin{array}{c}\text { Date of data } \\
\text { acquisition }\end{array}$ & $\begin{array}{c}\text { MODIS } \\
\text { MOD10A1 }\end{array}$ & $\begin{array}{c}\text { Sentinel- } \\
\text { 3A }\end{array}$ \\
\hline 29/Sept/2018 & 0.89 & 0.88 \\
\hline 04/June/2017 & 0.68 & 0.66 \\
\hline
\end{tabular}

Table 3. Comparison of normalized SCA values obtained from MODIS MOD10A1 and Sentinel-3A
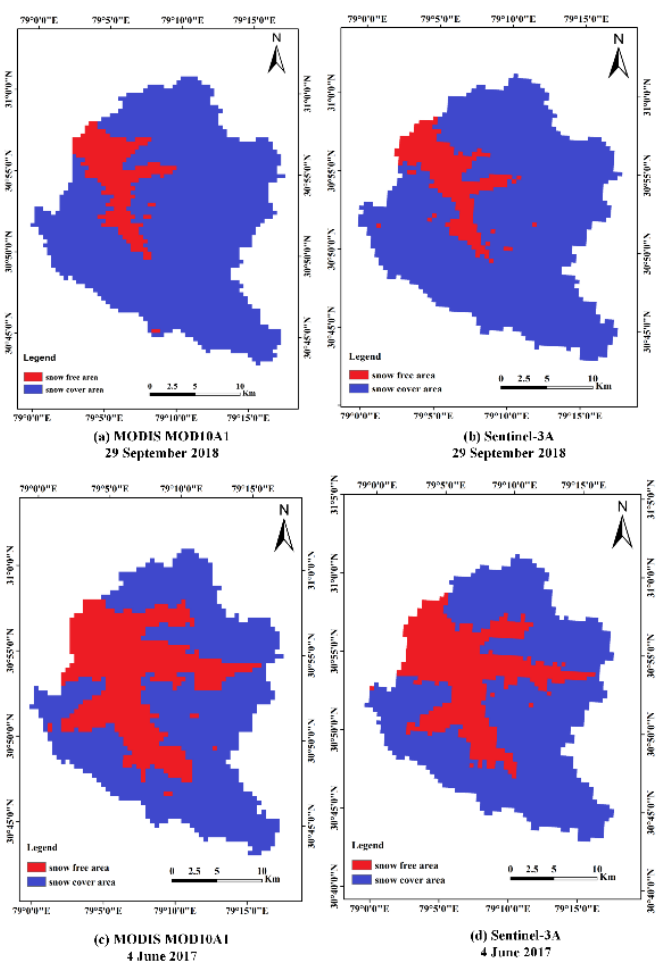

Figure 6. Comparison of Snow Cover Maps between Sentinel3A and MODIS MOD10A1 product for same dates

\section{CONCLUSION}

This study explores the possible use of multi source satellite data for extraction of SCA thereby reducing data gaps and temporal interval between two successive cloud free images. The study shows variation of SDC on a daily scale with much improved interpolated values by significantly reducing the temporal interval between two successive cloud free satellite data. This method may significantly enhance the accuracy of simulated daily snowmelt and bring the curve more closer to actual snowmelt curve.

The generation of SDC from normalized values of SCA for six snow melt seasons of Gangotri basin provides important conclusions about the nature of SDC. The average SDC starts from its peak value and gradually decreases till end of July. The curve reaches to its minimum snow cover at the end of July and almost remain constant for complete month of August till mid of September. With the occurrence of snowfall in the basin, snow cover increases and SDC shows a rise till end of September. More importantly, the variation of SDC for Gangotri basin may now be defined with the help of mathematical expression that is obtained by using regression analysis technique for snow melt season of the basin. A significant amount of improvement has been obtained in $\mathrm{R}^{2}$ value of the curve for snow melt period after splitting the average SDC for entire season to smaller parts based on different nature of SDC during different period of time.

The work highlights successful integration of satellite data from multiple sources, such as, MODIS MOD10A1 product, Landsat 8, Sentinel-2A and Sentinel-3A, to generate SDC with reduced data gaps and temporal interval. However, the accuracy of average SDC and its mathematical representation may be refined by considering more number of snow melt seasons in further research. This may also lead to better representation of trend 
equation. With the availability of discharge data for a basin, the SDC derived from satellite data of various sources may be tested by modelling daily snowmelt coming out from a basin.

\section{ACKNOWLEDGEMENTS}

The authors would like to thank European Space Agency (ESA) for providing Sentinel-3A and Sentinel-2A datasets along with SNAP software free of cost. The authors would also like to thank U.S. Geological Survey (USGS) for providing Landsat 8 surface reflectance data and MODIS MOD10A1 snow cover product free of cost

\section{REFERENCES}

Aggarwal, S. P., Thakur, P. K., Nikam, B. R., Garg, V., 2014. Integrated approach for snowmelt run-off estimation using temperature index model, remote sensing and GIS. Current Science, 106(3), pp.397-407.

Dressler, K. A., Leavesley, G. H., Bales, R. C., Fassnacht, S. R., 2006. Evaluation of gridded snow water equivalent and satellite snow cover products for mountain basins in a hydrologic model. Hydrological Processes: An International Journal, 20(4), pp.673-688.

Firouzi, S., Sadeghian, M. S., 2016. Application of Snow Melt Runoff Model in a Mountainous Basin of Iran. Journal of Geoscience and Environment Protection, 4(02), pp.74.

Immerzeel, W.W., Droogers, P., De Jong, S. M., Bierkens, M. F. P., 2009. Large-scale monitoring of snow cover and runoff simulation in Himalayan river basins using remote sensing. Remote sensing of Environment, 113(1), pp.40-49.

Kolberg, S.A., Gottschalk, L., 2006. Updating of snow depletion curve with remote sensing data. Hydrological Processes: An International Journal, 20(11), pp.2363-2380.

Kulshrestha, S., Ramsankaran, R., Kumar, A., Arora, M., Kumar, A. R., 2018. Investigating the performance of snowmelt runoff model using temporally varying near-surface lapse rate in Western Himalayas. Current Science, 114(4), pp.808-813.
Negi, H. S., Singh, S. K., Kulkarni, A.V., Semwal, B. S., 2010. Field-based spectral reflectance measurements of seasonal snow cover in the Indian Himalaya. International Journal of Remote Sensing, 31(9), pp.2393-2417.

Salomonson, V.V., Appel, I., 2004. Estimating fractional snow cover from MODIS using the Normalized Difference Snow Index. Remote Sensing of Environment, 89(3), pp.351-360.

Srivastava, D., 2012. Status report on Gangotri glacier. Science and Engineering Research Board, Department of Science and Technology, New Delhi, Himalayan Glaciology Technical Report, 3, pp.21-25.

Steele, C., Dialesandro, J., James, D., Elias, E., Rango, A., Bleiweiss, M., 2017. Evaluating MODIS snow products for modelling snowmelt runoff: Case study of the Rio Grande headwaters. International Journal of Applied Earth Observation and Geoinformation, 63, pp.234-243.

Tangri, A. K., Chandra, R., Yadav, S. K. S., 2004. Temporal monitoring of the snout, equilibrium line and ablation zone of Gangotri glacier through remote sensing and GIS techniques-an attempt at deciphering the climatic variability. In Proceedings of Workshop on Gangotri glacier, pp. 26-28.

Tiwari, S., Kar, S. C., Bhatla, R., 2015. Snowfall and snowmelt variability over Himalayan region in inter-annual timescale. Aquatic Procedia, 4, pp.942-949.

Verma, P., Ghosh, S. K., 2019a. Classification of glacial lakes using integrated approach of DFPS technique and gradient analysis using Sentinel 2A data. Geocarto International, 34(10), pp.1075-1088.

Verma, P., Ghosh, S. K., 2019b. Trend analysis of Climatic Research Unit temperature dataset for Gangotri glacier, India. Dynamics of Atmospheres and Oceans, 85, pp.83-97.

Zhu, Z., Wang, S., Woodcock, C. E., 2015. Improvement and expansion of the Fmask algorithm: Cloud, cloud shadow, and snow detection for Landsats 4-7, 8, and Sentinel 2 images. Remote Sensing of Environment, 159, pp.269-277. 